\title{
Fatores intervenientes na qualidade de vida de trabalhadores de enfermagem em jornada noturna
}

RESUMO |Objetivo: analisar os fatores intervenientes na qualidade de vida de trabalhadores de enfermagem em jornada noturna. Método: estudo analítico, transversal, quantitativo, realizado com 105 profissionais de enfermagem de um hospital com jornada noturna. Utilizaram-se questionários para avaliação socioeconômica e demográfica e da qualidade de vida. Os dados foram discutidos por meio de análise bivariada e análise comparativa, com nível de significância de $5 \%(p \leq 0,05)$. Resultados: verificouse associação estatisticamente significante entre a qualidade de vida geral e as variáveis: renda familiar de até quatro salários mínimos $(p=0,02)$, inatividade física $(p=0,01)$, tempo de trabalho na instituição $(p=0,02)$ e de atuação no período noturno $(p=0,01)$ superiores a 11 anos. Os domínios psicológico, físico e meio ambiente interferiram negativamente na qualidade de vida dos sujeitos, apesar destes terem classificado-a como boa. Conclusão: portanto, os serviços de saúde devem adotar medidas para proteger a saúde de seus trabalhadores da influência de fatores profissionais.

Palavras-chaves: Qualidade de vida; Fatores socioeconômicos; Jornada de trabalho em turnos; Atenção terciária à saúde; Profissionais de enfermagem.

\begin{abstract}
Objective: to analyze the intervening factors in the quality of life of nursing workers working at night. Method: analytical, cross-sectional, quantitative study carried out with 105 nursing professionals from a hospital with a night shift. Questionnaires were used for socioeconomic and demographic and quality of life assessments. The data were discussed using bivariate analysis and comparative analysis, with a significance level of $5 \%(p \leq 0.05)$. Results: there was a statistically significant association between the general quality of life and the variables: family income of up to four minimum wages ( $p=0.02$ ), physical inactivity $(p=0.01)$, working time at the institution $(p=0.02)$ and working at night $(p=0.01)$ over 11 years. The psychological, physical and environmental domains negatively interfered with the subjects' quality of life, despite the fact that they classified it as good. Conclusion: therefore, health services must adopt measures to protect the health of their workers from the influence of professional factors.
\end{abstract}

Keywords: Quality of life; Socioeconomic factors; Shift work schedule; Tertiary health care; Nurse practitioners.

RESUMEN | Objetivo: analizar los factores que intervienen en la calidad de vida de trabajadores de enfermería que laboran de noche. Método: estudio analítico, transversal y cuantitativo realizado con 105 profesionales de enfermería nocturnos de un hospital. Se utilizaron cuestionarios para evaluaciones socioeconómicas, demográficas y de calidad de vida. Los datos se discutieron mediante análisis bivariada y análisis comparativo, con un nivel de significancia del 5\% ( $p \leq 0.05$ ). Resultados: hubo asociación estadísticamente significativa entre la calidad de vida general y las variables: ingreso familiar de hasta cuatro salarios mínimos $(p=0,02)$, inactividad física $(p=0.01)$, tiempo de trabajo en la institución $(p=0,02)$ y trabajo nocturno $(p=0,01)$ durante 11 años. Los dominios psicológico, físico y ambiental interfirieron negativamente en la calidad de vida de los sujetos, a pesar de clasificársela como buena. Conclusión: por tanto, los servicios de salud deben adoptar medidas para proteger la salud de sus trabajadores de la influencia de factores profesionales.

Palabras claves: Calidad de vida; Factores socioeconómicos; Horario de trabajo por turnos; Atención terciaria de salud; Enfermeras practicantes.

\section{Patrick Leonardo Nogueira da Silva}

Enfermeiro, Mestrando pelo Programa de Pós-Graduação em Cuidado Primário em Saúde da Universidade Estadual de Montes Claros (PPGCPS/UNIMONTES). Montes Claros, MG, Brasil.

ORCID: 0000-0003-2399-9526

\section{Isabelle Leite Pereira}

Enfermeira pela Universidade Estadual de Montes Claros (UNIMONTES). Montes Claros, MG, Brasil.

ORCID: 0000-0003-0035-0257

Ana Patrícia Fonseca Coelho Galvão
Enfermeira, Mestre em Saúde e Ambiente,
Professora do Departamento de Enferma-
gem da Universidade Ceuma (UNICEU-
MA). São Luís, MA, Brasil.
ORCID: 0000-0003-3376-5678
Mirela Lopes de Figueiredo
Enfermeira, Doutora em Enfermagem, Pro-
fessora do Departamento de Enfermagem
da Universidade Estadual de Montes Claros
(UNIMONTES). Montes Claros, MG, Brasil.
ORCID: 0000-0001-7625-1787

\section{Ana Patrícia Fonseca Coelho Galvão}

Enfermeira, Mestre em Saúde e Ambiente, gem da Universidade Ceuma (UNICEUMA). São Luís, MA, Brasil.

\section{Mirela Lopes de Figueiredo}

Enfermeira, Doutora em Enfermagem, Proda Universidade Estadual de Montes Claros ORCID: 0000-0001-7625-1787

\section{Carolina dos Reis Alves}

Enfermeira, Doutora em Ciências da Saúde, Professora do Departamento de Enfermagem da Faculdade Santo Agostinho (FASA). Montes Claros, MG, Brasil.

ORCID: 0000-0003-2107-6306

\section{Aurelina Gomes e Martins}

Enfermeira, Mestre em Saúde Pública, Professora do Departamento de Enfermagem da Universidade Estadual de Montes Claros (UNIMONTES). Montes Claros, MG, Brasil. ORCID: 0000-0003-3582-8994 


\section{INTRODUÇÃO}

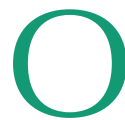
homem tem buscado amenizar os seus esforços na luta pela sobrevivência desde seus primórdios, e, como conseqüência, a busca pela qualidade de vida (QV) não é recente. Data dos primórdios da civilização humana a preocupação com a QV no trabalho, pois desde aquela época se tem relatos de que era constante a busca por melhores formas de executar uma tarefa, objetivando sempre melhores condições de trabalho e bem-estar(1). No entanto, foi com o advento da Revolução Industrial e a sistematização dos métodos de produção nos séculos XVIII e XIX que as condições de trabalho e sua influência sobre a produção passaram a ser analisadas e já destacava a influência da remuneração sobre a satisfação dos trabalhadores e, conseqüentemente, sobre o aumento da produtividade(2). Numa suposta harmonia de interesses entre patrões e empregados, afirmaria que a prosperidade dos trabalhadores estaria associada à prosperidade dos patrões, ainda que de uma forma eminentemente socioeconômica, o que levou a entender que a satisfação do funcionário influenciava na produção e, conseqüentemente, na lucratividade ${ }^{(1-2)}$.

Evoluídas as concepções, tem-se que a QV é, conforme a Organização Mundial da Saúde (OMS), a percepção do indivíduo quanto à sua posição na vida, tendo por base o contexto da sua cultura e do sistema de valores nos quais ele está inserido e em relação aos seus objetivos, expectativas, padrões e preocupações(3). Todavia, o termo QV implica em um enfoque subjetivo que naturalmente derivam várias definições. E para orientar essa concepção, o Ministério da Saúde (MS) conceitua "QV" associando o termo ao processo de satisfação humana em todos os aspectos, ou seja, com o "todo - que tem como referência noções subjetiva de conforto, bem-estar e realização individual e coletiva". Nesse caso, o conceito de QV guarda relatos com aspectos da indivi- dualidade e da subjetividade de cada sujeito com base no seu próprio julgamento pessoal(4). Dessa maneira, podemos compreender que a QV pode ser alcançada a partir da obtenção da satisfação e realização pessoal, profissional e social e, consequentemente, colocam o trabalho no pensamento central da QV, porque é por meio dele que as pessoas têm procurado satisfazer suas aspirações ${ }^{(5)}$.

O trabalho é parte integrante e essencial da vida humana e, dependendo da forma como é executado, pode ser gerador de fatores desgastantes e potencializar a dor dos processos saúde-doença ${ }^{(6)}$. A possível desarmonia na relação homem-trabalho e, principalmente, nos processos de trabalho, pode possibilitar a ocorrência de alterações na saúde do trabalhador. Isso tem sido um foco estudado constantemente, por exemplo, na área da saúde, em especial junto aos profissionais da enfermagem, tendo em vista, principalmente, o ambiente de trabalho que, neste caso, se torna ainda mais complexo que outros setores, já que o peso desta profissão está no fato do dever de cuidar de outras vidas ${ }^{(7)}$. A enfermagem é uma profissão que demanda maiores cuidados, sobretudo, por trabalhar em um ambiente laboral propício a afetar de forma mais severa a QV dos profissionais, seja a curto, médio ou longo prazo. Daí a importância de se avaliar com maior freqüência a QV dos profissionais da saúde, em especial da enfermagem ${ }^{(8)}$.

A avaliação da QV da equipe de enfermagem oferece subsídios para melhorar o processo de trabalho em saúde, a prática clínica, a relação profissional-usuário e orientar a (re)definição de políticas públicas específicas para esses profissionais no desempenho de suas funções. E o impacto pode ser duplo, ou seja, a melhoria das condições de vida e de trabalho desses profissionais pode gerar um impacto positivo na saúde, tanto dos enfermeiros quanto da população por eles assistida ${ }^{(9)}$. Contudo, esta não é uma tarefa fácil, especialmente porque os profissionais da saúde que trabalham no ambiente hos- pitalar possuem particularidades laborais que dificultam ainda mais a avaliação e, principalmente, o cuidado com sua QV ${ }^{(10)}$. $\mathrm{O}$ fato de terem que garantir um serviço em tempo integral com uma carga horária diária maior que o normal, mesmo que intercalada, em dois turnos ou em plantões variados, pois não são incomuns que estes profissionais procurem outros empregos, ou outras formas para subsidiar melhorias aos seus recursos financeiros. Por isso, tem sido freqüente a observação de estudos que vêm avaliando os problemas que este tipo de organização no trabalho causaà saúde do trabalhador ${ }^{(7)}$.

A queda da QV do profissional da saúde é ainda maior quando este trabaIha no turno noturno, pois os seres humanos são biologicamente programados para desenvolverem atividades físicas e mentais de dia e descansarem à noite, consequentemente, o seu corpo sentirá as mudanças e se esforçaráainda mais pararealizar intervenções neste que seria o período de repouso, o que poderá gerar alterações biológicas na temperatura corporal, níveis hormonais, alterações psíquicas e comportamentais ou no desempenho cognitivo. Existem benefícios para os empregados que trabalha no período noturno, especialmente o fato de os enfermeiros terem maior autonomia no desempenho de suas funções, já que não possuem a mesma carga de chefia que os profissionais que atuam no período diurno. Mas, reconhecem que disso decorre também um aspecto negativo influenciado pela sobrecarga de funções ${ }^{(11)}$.

Outro fator a ser analisado na avaliação da QV dos profissionais de enfermagem que trabalham no período noturno, está relacionado ao seu humor, especialmente, por saber que é muito importante para o processo de efetivação do cuidado dos pacientes que estes profissionais estejam inteiramente satisfeitos de modo a transmitir satisfação, segurança e qualidade na execução de tarefas previstas e imprevistas $^{(7)}$. Os profissionais de enfermagem necessitam de um estado de alerta incessante, o que exige plena saúde física, 
mental e emocional, estes estão ligados diretamente ao cuidado do ser humano, ao processo de cura e reabilitação de pacientes, de modo que pequenos descuidos ou falhas podem resultar em complicações ${ }^{(12)}$.

Considerando a relevância desta temática levantou-se o seguinte problema de pesquisa: quais os fatores intervenientes na QV de trabalhadores de enfermagem em jornada noturna em um hospital-escola, na cidade de Montes Claros/MG?

Para tanto, optou-se pela definição de QV proposta pela Organização Mundial da Saúde (OMS), a qual leva em conta a percepção do indivíduo e suas relações com o meio ambiente. Estadefine QV como uma percepção individual da posição do indivíduo na vida, no âmbito de sua cultura e sistema de valores no qual está inserido e em relação aos seus objetivos, expectativas, padrões e preocupações. Trata-se de um conceito de alcance abrangente afetado de forma complexa pela saúde física, estado psicológico, nível de independência, relações sociais e relações com as características do meio ambiente do indivíduo ${ }^{(13)}$.

Sendo assim, este estudo teve como objetivo analisar os fatores intervenientes na QV de trabalhadores de enfermagem em jornada noturna.

\section{MÉTODOS}

Artigo da monografia intitulada "Influência do trabalho noturno na QV de trabaIhadores de enfermagem", apresentada ao Departamento de Enfermagem da Universidade Estadual de Montes Claros/UNIMONTES. Montes Claros (MG), Brasil. 2015.

Trata-se de um estudo analítico, transversal, com abordagem quantitativa, realizado no Hospital Universitário Clemente de Faria (HUCF) do município de Montes Claros, Minas Gerais. A amostragem do estudo foi composta por 161 profissionais de enfermagem que trabalham no período noturno. Destes, 129 são técnicos de enfermagem, 31 são enfermeiros e um é auxiliar de enfermagem. A amostra contou com 105 profissionais dos di- versos setores hospitalares. Foram excluídos 20 profissionais que se encontravam de férias durante o período da realização da coleta de dados e 36 profissionais que se recusaram em participar do estudo.

O método de amostragem foi por conveniência, tendo em vista a acessibilidade dos participantes pesquisados. Esta técnica é muito utilizada e fundamenta-se em captar uma amostra da população que seja acessível. Ou seja, os indivíduos empregados nessa pesquisa são selecionados porque eles estão prontamente disponíveis, não porque eles foram selecionados por meio de um critério estatístico. Geralmente, essa conveniência representa uma maior facilidade operacional e baixo custo de amostragem, porém tem como conseqüência a incapacidade de fazer afirmações gerais com rigor estatístico sobre a população ${ }^{(14)}$.

Foi enviado à Secretaria Municipal de Saúde de Montes Claros (SMS-MOC), bem como à Diretoria Clínica do HUCF, o projeto de pesquisa, uma carta de apresentação e um Termo de Consentimento Institucional (TCl), para autorização da pesquisa. As instituições foram devidamente orientadas quanto às suas diretrizes e as mesmas assinaram o $\mathrm{TCl}$ de modo a autorizar a realização da pesquisa. A coleta de dados foi realizada no $1^{\circ}$ semestre de 2015, durante o mês de janeiro pelo pesquisador responsável.

O HUCF integra a estrutura da Universidade Estadual de Montes Claros (UNIMONTES), sendo um hospital de ensino totalmente público e dedica $100 \%$ da sua capacidade instalada ao Sistema Único de Saúde (SUS). Possui 171 leitos hospitalares e 10 leitos de internação domiciliar (HU em Casa).

Para a realização da coleta de dados foram utilizados dois instrumentos, sendo o primeiro um questionário socioeconômico e demográfico (ANEXO I), de elaboração própria, e o segundo um questionário genérico, validado, sobre QV, denominado Instrumento Abreviado de Avaliação de QV da OMS (WHOQOL-Bref)(15) (ANE$X O$ II), que consiste na versão abreviada do WHOQOL-100, ambos desenvolvidos pelo Grupo de QV da OMS.

O questionário socioeconômico e demográfico foi composto pelas seguintes variáveis: sexo; faixa etária; estado civil categorizado em com e sem companheiro; cor autodeclarada categorizada em brancos, pardos e negros; participação na vida econômica do grupo familiar; renda do grupo familiar; o tipo de imóvel em que reside; religião; e se tem filhos e a quantidade. Também foram avaliadas variáveis relacionadas às características pessoais e profissionais: se fuma; se consome bebidas alcoólicas; qual atividade ocupa-se mais no tempo de folga; e se pratica atividade física e qual. Quanto às características profissionais, investigou-se o cargo exercido no hospital; tempo de trabalho na instituição; quanto tempo trabalho no período noturno; e motivo da opção pelo trabalho a noite.

A versão em português do WHOQOL-bref foi desenvolvida no Centro WHOQOL para o Brasil e contém 26 questões: duas questões gerais, que não entram no cálculo dos escores dos domínios, sendo que uma se refere à VIDA e a outra, à SAÚDE. As demais 24 perguntas são relativas a quatro domínios e suas respectivas facetas, como segue: Domínio I - físico, focalizando as seguintes facetas: dor e desconforto, energia e fadiga, sono e repouso, atividades da vida cotidiana, dependência de medicação ou de tratamentos, capacidade de trabalho; Domínio II - psicológico, cujas facetas são: sentimentos positivos, pensar, aprender, memória e concentração, autoestima, imagem corporal e aparência, sentimentos negativos, espiritualidade, religiosidade e crenças pessoais; Domínio III - relações sociais, que inclui as facetas a seguir: relações pessoais, suporte (apoio) social, atividade sexual; Domínio IV - meio ambiente, abordando as facetas: segurança física e proteção, ambiente no lar, recursos financeiros, cuidados de saúde e sociais: disponibilidade e qualidade, oportunidades de adquirir novas informações e habilidades, participação 
em, e oportunidades de recreação/lazer, ambiente físico: poluição, ruído, trânsito, clima, transporte. Este instrumento considera os últimos quinze dias vividos pelos respondentes. Os escores finais de cada domínio consideram as respostas de cada questão que compõe o domínio, sendo que quanto mais alto o escore melhor será avaliada a QV. A classificação tanto do domínio quanto das facetas foi estabelecida de acordo com as seguintes definições: necessita melhorar (quando for de 1 até 2,9 ); regular (3 até 3,9); boa (4 até 4,9 ) e muito boa ${ }^{(5)}$.

Após a coleta, os dados foram organizados em um banco de dados utilizando-se do programa estatístico Statistical Package for the Social Science (SPSS), versão $18.0 \AA$,e submetidos à análise descritiva com o uso de frequências absolutas e percentuais. Em seguida, realizou-se a análise bivariada empregando a comparação de médias de QV geral pelo Test T Student para amostras independentes, com a finalidade de comparar o escore geral da QV em relação às vari- áveis socioeconômicas e demográficas, bem como profissionais. Este teste levou em consideração os pressupostos do estudo, bem como a distribuição das variáveis quantitativas e a homocedasticidade. Além disso, foi efetuada uma análise comparativa dos aspectos socioeconômicos e demográficos por meio do cálculo de médias e valor de $p$ baseado no Test $T$ Student. Na análise comparativa e no Test T Student, foi utilizado o nível de significância de 5\% (p<0,05).

Os dados foram coletados em horários previamente acordados com os sujeitos, de forma a não interferir na realização das atividades profissionais dos mesmos. Antes de iniciar a coleta, os participantes foram devidamente orientados quanto às diretrizes do estudo na qual assinaram o Termo de Consentimento Livre e Esclarecido (TCLE) de modo a autorizar a realização da pesquisa.

O estudo obedeceu aos preceitos éticos estabelecidos pela Resolução n 466, de 12 de dezembro de 2012, do Conselho Nacional de Saúde (CNS), o qual regulamenta a realização de pesquisas envolvendo seres humanos ${ }^{(16)}$. O projeto de pesquisa foi apreciado e aprovado pelo Comitê de Ética em Pesquisada Universidade Estadual de Montes Claros (CEP UNIMONTES), via Plataforma Brasil, sob parecer consubstanciado $\mathrm{n}^{\circ}$ 911.265/2014, Certificado de Apresentação para Apreciação Ética (CAAE) $n^{\circ}$ 39684914.6.0000.5146.

\section{RESULTADOS E DISCUSSÃO}

Observou-se prevalência de profissionais de enfermagem do sexo feminino $(66,7 \%)$ na amostra total, sendo que a maior parte era constituída por técnicos de enfermagem $(70,5 \%)$, faixa etária entre $31-40$ anos $(62,9 \%)$, pardos $(63, \%)$, casado $(79,0 \%)$, é o principal responsável pelo sustento familiar $(44,8 \%)$, renda familiar igual ou superior a cinco salários mínimos (SM) (39,0\%), reside em imóvel próprio $(72,4 \%)$, tem dois filhos $(32,4 \%)$, católicos $(68,6 \%)$ e não estudam atualmente $(61,9 \%)$ (Tabela 1$)$.

Tabela 1 - Aspectos socioeconômicos e demográficos dos profissionais de enfermagem em jornada noturna de um hospitalescola do norte de Minas Gerais. Montes Claros, MG, 2015. $(n=105)$

\section{Categoria profissional}

Variáveis
(Socioeconômicas e demográficas)

Técnico de Enfermagem
Auxiliar de Enfermagem

\begin{tabular}{|c|c|c|c|c|c|c|c|c|}
\hline \multirow[t]{2}{*}{ (socioeconomicas e demograticas) } & & \multicolumn{2}{|c|}{ magem } & \multicolumn{2}{|c|}{ magem } & \multirow[b]{2}{*}{$\mathrm{n}$} & \multirow[b]{2}{*}{$\%$} \\
\hline & $\mathbf{n}$ & $\%$ & $\mathbf{n}$ & $\%$ & $\mathbf{n}$ & $\%$ & & \\
\hline \multicolumn{9}{|l|}{ Sexo } \\
\hline Feminino & 07 & 43,7 & 62 & 70,5 & 01 & 100,0 & 70 & 66,7 \\
\hline
\end{tabular}

Faixa etária (anos)

\begin{tabular}{lcccccccc}
\hline$[20,30]$ & 00 & 0,0 & 09 & 10,2 & 00 & 0,0 & 09 & 8,6 \\
\hline$[31,40]$ & 14 & 87,5 & 51 & 58,0 & 00 & 0,0 & 66 & 62,9 \\
\hline$[41,50]$ & 02 & 12,5 & 15 & 17,0 & 01 & 100,0 & 17 & 16,2 \\
\hline$[51,+]$ & 00 & 0,0 & 13 & 14,8 & 00 & 0,0 & 13 & 12,4 \\
\hline Cor/Raça autodeclarada & & & & & & & \\
\hline Branco & 08 & 50,0 & 16 & 18,2 & 00 & 0,0 & 24 & 22,9 \\
\hline Negro & 01 & 6,2 & 12 & 13,6 & 01 & 100,0 & 14 & 13,3 \\
\hline Pardo & 07 & 43,8 & 60 & 68,2 & 00 & 0,0 & 67 & 63,8 \\
\hline Estado civil & & & & & & & & \\
\hline Solteiro & 03 & 18,7 & 18 & 20,5 & 01 & 100,0 & 22 & 21,0
\end{tabular}




\begin{tabular}{|lccccccccc}
\hline Casado & 13 & 81,3 & 70 & 79,5 & 00 & 0,0 & 83 & 79,0 \\
\hline Participação financeira no GF & & & & & & & & \\
\hline Trabalho, mas recebo ajuda financeira da família. & 02 & 12,5 & 03 & 3,4 & 00 & 0,0 & 05 & 4,8 \\
\hline Sou responsável apenas pelo meu próprio sustento. & 02 & 12,5 & 05 & 5,7 & 00 & 0,0 & 07 & 6,7 \\
\hline Sou responsável pelo meu sustento e contribuo em casa. & 07 & 43,8 & 39 & 44,3 & 00 & 0,0 & 46 & 43,8 \\
\hline Sou o principal responsável pelo sustento da família. & 05 & 31,2 & 41 & 46,6 & 01 & 100,0 & 47 & 44,8 \\
\hline Renda do GF & & & & & & & & \\
\hline$<$ S SM & 00 & 0,0 & 03 & 3,4 & 00 & 0,0 & 03 & 2,9 \\
\hline 3 SM & 00 & 0,0 & 27 & 30,6 & 00 & 0,0 & 27 & 25,7 \\
\hline 4 SM & 04 & 25,0 & 29 & 33,0 & 01 & 100,0 & 34 & 32,4 \\
\hline Z S SM & 12 & 75,0 & 29 & 33,0 & 00 & 0,0 & 41 & 39,0 \\
\hline
\end{tabular}

Tipo de imóvel que reside

\begin{tabular}{|lcccccccc|} 
Próprio & 10 & 62,4 & 65 & 73,9 & 01 & 100,0 & 76 & 72,4 \\
\hline Alugado & 03 & 18,8 & 08 & 9,1 & 00 & 0,0 & 11 & 10,5 \\
\hline Cedido & 00 & 0,0 & 04 & 4,5 & 00 & 0,0 & 04 & 3,8 \\
\hline Financiado & 03 & 18,8 & 10 & 11.4 & 00 & 0,0 & 13 & 12,4 \\
\hline Outra situação & 00 & $\mathbf{0 , 0}$ & $\mathbf{0 1}$ & $\mathbf{1 . 1}$ & $\mathbf{0 0}$ & $\mathbf{0 , 0}$ & $\mathbf{0 1}$ & $\mathbf{1 , 0}$ \\
\hline
\end{tabular}

Filhos

\begin{tabular}{lcccccccc|}
\hline Nenhum & 07 & 43,8 & 12 & 13,6 & 00 & 0,0 & 19 & 21,8 \\
\hline 01 & 02 & 12,5 & 23 & 26,1 & 00 & 0,0 & 25 & 22,9 \\
\hline 02 & 06 & 37,5 & 33 & 37,6 & 00 & 0,0 & 39 & 32,4 \\
\hline 03 ou + & 01 & 6,3 & 20 & 22,7 & 01 & 100,0 & 22 & 17,1 \\
\hline Religião & & & & & & & & \\
\hline Católico & 12 & 75,0 & 59 & 67,0 & 01 & 100,0 & 72 & 68,6 \\
\hline Evangélico & 01 & 6,3 & 22 & 25,0 & 00 & 0,0 & 23 & 21,9 \\
\hline Adventista & 01 & 6,3 & 03 & 3,4 & 00 & 0,0 & 04 & 3,8 \\
\hline Nenhuma & 02 & 12,5 & 04 & 4,5 & 00 & 0,0 & 06 & 5,7 \\
\hline Estuda atualmente & & & & & & & & \\
\hline Sim & 11 & 68,8 & 29 & 33,0 & 00 & 0,0 & 40 & 38,1 \\
\hline Não & 05 & 31,2 & 59 & 67,0 & 01 & 100,0 & 65 & 61,9 \\
\hline
\end{tabular}

Fonte: Coleta de dados, 2015.

GF $=$ Grupo Familiar. SM = Salários Mínimos.

A renda mensal familiar interferiu negativamente na QV dos sujeitos. Verificou-se correlação significativa $(p=0,02)$, com menores escores $83,0(\mathrm{DP} \pm 10,9)$ para os profissionais com renda de cinco ou mais salários mínimos (SM) até quatro SM e maiores escores $88,0(\mathrm{DP} \pm 8,8)$ para que tem renda até quatro $S M$, ou seja, os trabalhadores que possuem menor renda têm QV superior. A inatividade física foi um fator que também interferiu na QV, uma vez que ocorreu correlação signifi- cante $(p=0,01)$, evidenciada pelos escores maiores para quem não pratica atividade física, 88,9 $(\mathrm{DP} \pm 11,2)$, e inferiores para os que praticam atividade física 83,9 $(\mathrm{DP} \pm 9,2)$. Neste estudo, ainda se constatou correlação significativa entre a QV geral e o tempo de atuação na instituição, com melhor QV 89,9 $(\mathrm{DP} \pm 8,4)$ para os profissionais que tem de 11 ou mais anos de tempo de trabalho na instituição e menor $84,9(\mathrm{DP} \pm 11,3)$ para os tem de 1 a 10 anos de atuação na instituição cenário da pesquisa. Em relação a tempo de atuação no período noturno, houve correlação $(p=0,01)$, e escores 90,5 ( $\mathrm{DP} \pm 11,3)$ para os profissionais que tem de 11 ou mais anos de tempo de atuação no turno noturno e menor $84,9(\mathrm{DP} \pm 11,3)$ para os tem de 1 a 10 anos de atuação no turno noturno, mostrando QV melhor para quem tem 11 ou mais anos de atuação no período noturno (Tabela 2).

Quanto às demais características sexo, idade, raça, estado civil, participa- 
Tabela 2 - Associação do escore médio do domínio da QV geral com as características socioeconômicas e demográficas e profissionais da equipe de enfermagem que trabalha no turno noturno. Montes Claros, MG, 2015. ( $n=105)$

\section{Variáveis}

(socioeconômicas e demográficas)

\section{Renda mensal do GF}

\begin{tabular}{lllll} 
Até 4 SM & 30 & 28,6 & $88,1 \pm 10,9$ & 0,02 \\
$\geq 5$ SM & 75 & 71,4 & $83,0 \pm 8,8$ & \\
\hline
\end{tabular}

\section{Atividade física que pratica}

\begin{tabular}{lllll} 
Não pratica atividade física & 58 & 55,2 & $88,9 \pm 11,2$ & 0,01 \\
\hline Pratica atividade física & 47 & 44,8 & $83,9 \pm 9,2$ &
\end{tabular}

\section{Tempo na instituição (anos)}

$$
[1,10]
$$

$[11,+]$

$\begin{array}{ccc}69 & 65,7 & 84,9 \pm 11,3 \\ 36 & 34,3 & 89,9 \pm 8,4\end{array}$

\section{Tempo de atuação à noite (anos)}

\begin{tabular}{lllll}
{$[1,10]$} & 74 & 70,5 & $85,0 \pm 10,0$ & 0,01 \\
\hline$[11,+]$ & 31 & 29,5 & $90,5 \pm 11,3$ &
\end{tabular}

Fonte: Coleta de dados, 2015.

p-Valor: significância estatística $(p \leq 0,05)$ a partir do teste T student.

*Escore médio da QV geral apresentados em médias e desvio padrão.

MAP = Média Aritmética Ponderada $. \mathrm{DP}=$ Desvio Padrão. $\mathrm{SM}=$ Salários Mínimos. ção financeira do grupo familiar, religião, filhos, atividades que mais ocupam tempo nas folgas, consumo de bebidas alcoólicas, tabagismo, motivo pelo a opção do trabalho noturno e outro vínculo empregatício - não foram encontradas associações significantes em relação à QV geral.

Quanto ao tempo de exercício profissional na instituição, houve prevalência de profissionais entre seis e 10 anos $(52,4 \%)$, sendo a maior parte constituída por técnicos de enfermagem $(51,1 \%)$. Tendo em vista o turno de atuação, prevaleceram profissionais com o mesmo período de seis a 10 anos, tanto na instituição, quanto atuantes durante o turno noturno $(49,5 \%)$. Em se tratando do motivo pela opção em trabalhar durante a noite, $57,1 \%$ informaram ser pela disponibilidade para estar com a família, tendo em vista que a maioria dos profissionais é do sexo feminino, apresentam jornada dupla e tem que se dividir entre a família e o trabalho (Tabela 3).

Tabela 3 - Aspectos demográficos relacionados à situação profissional da equipe de enfermagem que trabalha no período noturno em um hospital-escola do norte de Minas Gerais. Montes Claros, MG, 2015. ( $n=105)$

\section{Categoria profissional}

\section{Variáveis \\ (socioeconômica e demográfica)}

\section{Técnico de Enfer-} magem

\section{Auxiliar de Enfer- magem}

$\begin{array}{llllllll}\mathbf{n} & \% & \mathbf{n} & \% & \mathbf{n} & \% & \mathbf{n} & \%\end{array}$

\section{Tempo na instituição (anos)}

\begin{tabular}{lcccccccc}
{$[1,5]$} & 03 & 8,8 & 11 & 12,5 & 00 & 0,0 & 14 & 13,3 \\
\hline$[6,10]$ & 10 & 62,4 & 45 & 51,1 & 00 & 0,0 & 55 & 52,4 \\
\hline$[11,20]$ & 03 & 18,8 & 25 & 28,4 & 00 & 0,0 & 28 & 26,7 \\
{$[21,+]$} & 00 & 0,0 & 07 & 8,0 & 01 & 100,0 & 08 & 7,6
\end{tabular}

Tempo de atuação à noite (anos)

$\begin{array}{lccccccccc}{[1,5]} & 04 & 25,0 & 18 & 20,5 & 00 & 0,0 & 22 & 21,0 \\ {[6,10]} & 10 & 62,4 & 42 & 47,7 & 00 & 0,0 & 52 & 49,5 \\ {[11,20]} & 01 & 6,3 & 24 & 27,3 & 00 & 0,0 & 25 & 23,8 \\ {[21,+]} & 01 & 6,3 & 04 & 4,5 & 01 & 100,0 & 06 & 5,7\end{array}$

\section{Motivo da opção pelo trabalho noturno}

\begin{tabular}{|lcccccccc|}
\hline Questão salarial & 00 & 0,0 & 07 & 8,0 & 00 & 0,0 & 07 & 6,7 \\
\hline Disponibilidade para a família & 02 & 12,5 & 20 & 22,7 & 00 & 0,0 & 22 & 20,9 \\
\hline Possui outro vinculo empregatício & 09 & 56,3 & 51 & 58,0 & 01 & 100,0 & 61 & 58,0 \\
\hline Estudos em geral & 05 & 31,2 & 10 & 11,3 & 00 & 0,0 & 15 & 14,4 \\
\hline
\end{tabular}


Possui outro vínculo

\begin{tabular}{|c|c|c|c|c|c|c|c|c|}
\hline Sim & 14 & 87,5 & 57 & 68,4 & 00 & 0,0 & 71 & 67,6 \\
\hline Não & 02 & 12,5 & 31 & 35,2 & 01 & 100,0 & 34 & 32,4 \\
\hline
\end{tabular}

Fonte: coleta de dados, 2015.

Assim, analisando as informações sobre alguns hábitos de vida que poderiam interferir na QV dos sujeitos, ficou demonstrado que destes, apenas 5,7\% são tabagistas, 51,4\% não são etilistas e $36,2 \%$ só bebem socialmente. Ainda, $48,5 \%$ ocupam seu tempo de folga assistindo TV e 44,8\% não pratica atividades físicas. Percebeu-se, ainda, que os enfermeiros tendem a se exercitar mais que os técnicos em enfermagem, o que se relaciona com uma melhor QV. Disso, decorreu que o baixo nível de atividade física aliado ao estresse constante pode interferir diretamente na QV e na saúde desses profissionais. Quando questionados sobre como avaliam a sua QV, $53,4 \%$ consideraram sua QV boa, 30,5\% nem boa, nem ruim, e 9,5\% ruim, 1,9\% disseram ser muito ruim e apenas 5,7\% relataram ter uma QV muito boa. Sobre a satisfação com o estado de saúde 44,7\% se consideram satisfeitos com sua saúde e, 20,0\% relataram sentirem-se insatisfeitos, outros $26,7 \%$ disseram não estar nem satisfeitos nem insatisfeitos (Tabela 4).

Tabela 4 - Aspectos pessoais e sociais relacionados às categorias profissionais da equipe de enfermagem que trabalha no período noturno em um hospital-escola do norte de Minas Gerais. Montes Claros, MG, 2015. ( $n=105)$

\section{Categoria profissional}

Variáveis

(socioeconômica e demográfica)
Técnico de Enfermagem
Total magem

Fuma

$\begin{array}{lcccccccc}\text { Sim } & 15 & 93,8 & 84 & 95,5 & 00 & 0,0 & 99 & 94,3 \\ \text { Não } & 01 & 6,2 & 04 & 4,5 & 01 & 100,0 & 06 & 5,7\end{array}$

Freqüência de consumo de bebida alcoólica

\begin{tabular}{|c|c|c|c|c|c|c|c|c|}
\hline $1-2$ vezes por semana & 01 & 6,3 & 08 & 9,1 & 00 & 0,0 & 09 & 8,6 \\
\hline $3-5$ vezes por semana & 01 & 6,3 & 03 & 13,4 & 00 & 0,0 & 04 & 3,8 \\
\hline Não sou etilista & 10 & 62,4 & 43 & 48,9 & 01 & 100,0 & 54 & 51,4 \\
\hline \multicolumn{9}{|c|}{ Atividade que pratica nas folgas } \\
\hline Assistir TV & 03 & 18,8 & 47 & 53,4 & 01 & 100,0 & 51 & 48,5 \\
\hline Ouvir música & 01 & 6,3 & 07 & 8,0 & 00 & 0,0 & 08 & 7,6 \\
\hline Ir a bares/boates/similares & 00 & 0,0 & 03 & 3,4 & 00 & 0,0 & 03 & 2,9 \\
\hline Leitura & 06 & 37,4 & 13 & 14,8 & 00 & 0,0 & 19 & 18,1 \\
\hline Atividade física & 02 & 12,5 & 06 & 6,8 & 00 & 0,0 & 08 & 7,6 \\
\hline Caminhada & 05 & 31,3 & 25 & 28,4 & 00 & 0,0 & 30 & 28,5 \\
\hline Academia & 01 & 6,3 & 08 & 9,1 & 00 & 0,0 & 09 & 8,6 \\
\hline Natação & 01 & 6,3 & 02 & 2,3 & 00 & 0,0 & 03 & 2,9 \\
\hline Trilha & 00 & 0,0 & 01 & 1,2 & 00 & 0,0 & 01 & 1,0 \\
\hline Outras & 01 & 6,3 & 04 & 4,5 & 00 & 0,0 & 05 & 4,8 \\
\hline Nenhuma & 07 & 43,5 & 39 & 44,3 & 01 & 100,0 & 47 & 44,7 \\
\hline
\end{tabular}




\begin{tabular}{|lcccccccc}
\hline Como você avalia a sua QV & & & & & & & \\
\hline Muito ruim & 00 & 0,0 & 02 & 2,3 & 00 & 0,0 & 02 & 1,9 \\
\hline Ruim & 01 & 6,3 & 09 & 10,2 & 00 & 0,0 & 10 & 9,5 \\
\hline Nem ruim, nem boa & 04 & 25,0 & 28 & 31,8 & 00 & 0,0 & 32 & 30,5 \\
\hline Boa & 11 & 68,7 & 43 & 48,9 & 01 & 100,0 & 55 & 53,4 \\
\hline Muito boa & 00 & 0,0 & 06 & 6,8 & 00 & 0,0 & 06 & 5,7 \\
\hline Quão satisfeito você esta com sua saúde & & & & & & & & \\
\hline Muito insatisfeito & 00 & 0,0 & 03 & 3,4 & 00 & 0,0 & 03 & 2,9 \\
\hline Insatisfeito & 06 & 37,5 & 15 & 17,0 & 00 & 0,0 & 21 & 20,0 \\
\hline Nem satisfeito, nem insatisfeito & 03 & 18,8 & 24 & 27,3 & 01 & 100,0 & 28 & 26,7 \\
\hline Satisfeito & 07 & 43,7 & 40 & 45,5 & 00 & 0,0 & 47 & 44,7 \\
\hline Muito satisfeito & 00 & 0,0 & 06 & 6,8 & 00 & 0,0 & 06 & 5,7 \\
\hline
\end{tabular}

Fonte: coleta de dados, 2015.

A tabela 5 demonstra haver uma diferença significativa entre os domínios estudados. Os domínios psicológico, físico e de meio ambiente se apresentaram com menor escore $(p=0,008, p=0,029$ e $\mathrm{p}=0,041)$ respectivamente, apresentando desta forma maior interferência na QV dos sujeitos. Quanto maior o escore, meIhor a QV, e que valores de $\mathrm{p}$ entre 0,01 a 0,029 devem ser consideradas por serem aspectos que necessitam de melhorias imediatas e valores de $p$ entre 0,03 a 0,039 demonstram domínios que se encontram regulares.
Em relação ao perfil socioeconômico e demográfico, dos 105 profissionais pesquisados, constatou-se que $66,7 \%$ são do sexo feminino, $62,9 \%$ têm idade entre 31-40 anos. Diversos estudos apontam umatendência à feminilização da força de trabalho no setor saúde, predominância que é jus $\neg$ tificada pelo fato de os cursos da área da saúde possuírem características histórico-sociais que atraem mais estudantes desse $\operatorname{sexo}^{(5,8,17)}$. O trabalho desenvolvido no ambiente hospitalar é mais prejudicial às mulheres tendo em vista que muitas das atividades ali desen- volvidas exigem grande força muscular e, conseqüentemente, imprimem maior desgaste físico ${ }^{(10,13)}$.

Com relação à idade, a equipe de enfermagem do HUCF apresentou uma média de 35 anos, o que segundo o Instituto Brasileiro de Geografia e Estatística (IBGE), no ano de 2010, a equipe é constituída por adultos jovens. Esta é uma condição positiva para o desenvolvimento das atividades laborais e para o desempenho de uma boa QV. Existe uma relação intensa de risco entre o aumento da média de idade e a possibilidade de

Tabela 5 - Análise dos fatores intervenientes na QV em relação ao WHOQOL-Breve, dos dados coletados da equipe de enfermagem que trabalha no período noturno em um hospital-escola do norte de Minas Gerais. Montes Claros, MG, 2015. (n=105)

\begin{tabular}{|c|c|c|c|c|c|c|c|c|c|}
\hline \multirow{3}{*}{ Variáveis } & \multirow{3}{*}{ n } & \multicolumn{8}{|c|}{ DOMÍNIOS } \\
\hline & & \multicolumn{2}{|c|}{ FÍSICO } & \multicolumn{2}{|c|}{ PSICOLÓGICO } & \multicolumn{2}{|c|}{$\begin{array}{l}\text { RELAÇÕES } \\
\text { SOCIAIS }\end{array}$} & \multicolumn{2}{|c|}{ MEIO AMBIENTE } \\
\hline & & Média & $\mathbf{p}$ & Média & p & Média & $\mathbf{p}$ & Média & $\mathbf{p}$ \\
\hline \multicolumn{10}{|l|}{ Sexo } \\
\hline Feminino & 70 & 61,17 & 0,02 & 76,15 & 0,008 & 75,18 & 0,13 & 57,59 & 0,04 \\
\hline Masculino & 35 & 54,21 & & 65,19 & & 69,13 & & 52,48 & \\
\hline \multicolumn{10}{|l|}{ Estado civil } \\
\hline Casado & 83 & 59,36 & 0,91 & 72,21 & 0,13 & 73,54 & 0,83 & 55,48 & 0,04 \\
\hline Solteiro & 22 & 59,48 & & 75,63 & & 74,87 & & 58,82 & \\
\hline \multicolumn{10}{|l|}{ Categoria profissional } \\
\hline Enfermeiro & 16 & 60,03 & 0,91 & 76,14 & 0,008 & 74,83 & 0,24 & 62,17 & 0,01 \\
\hline Técnico de enfermagem & 88 & 58,26 & & 67,32 & & 70,52 & & 52,75 & \\
\hline Auxiliar de enfermagem & 01 & 59,67 & & 78,33 & & 75,26 & & 58,56 & \\
\hline
\end{tabular}

Fonte: Coleta de dados, 2015. 
interferência negativa no desempenho da QV dos profissionais de enfermagem(5). Indivíduos que se encontram na faixa de idade entre 41-50 anos possuem maior tendência ao desequilíbrio estrutural, o que configura uma maior predisposição à diminuição da $\mathrm{QV}^{(18)}$. Em contrapartida, as pessoas mais jovens têm maior facilidade à adaptação noturna e, portanto, menos prejuízo em sua QV ao desenvolverem trabalhos no período noturno ${ }^{(19)}$.

Em relação à raça, o estudo demonstrou que $63,8 \%$ se consideram de cor parda e $22,9 \%$ de cor branca. No que se refere ao estado civil, 79,0\% são casados e $72,4 \%$ tem filhos. A porcentagem dos sujeitos com estado civil casados não se diferenciou da caracterização apresentada em outros estudos que mais de 50\% eram $\operatorname{casados}^{(3,8,20)}$. Autores afirmam que indivíduos casados apresentam maior tendência em possuírem melhor QV devido ao conforto e apoio emocional e financeiro que esta proporciona, mas, complementam que o fato de ser casado, principalmente para as mulheres, pode representar um empecilho à $\mathrm{QV}$, por trazer consigo maiores responsabilidades e um maior acúmulo de funções o que resultaria em maior sobrecarga e maiores desgastes físicos e emocionais ${ }^{(8,13,17,19,20)}$.

Em relação à categoria profissional, 83,8\% dos profissionais de enfermagem do serviço são técnicos em enfermagem. Outros estudos desenvolvidos também demonstraram a predominância de técnicos de enfermagem nos serviços de saúde, conforme dados apresentados pelo Conselho Federal de Enfermagem (COFEN) no ano de 2014, no Brasil, os técnicos de enfermagem corresponderam a um percentual de $43 \%$ e os enfermeiros corresponderam a apenas 20\% dos profissionais de enfermagem ${ }^{(21)}$.Observando o tempo de trabalho na instituição, $52,4 \%$ trabalham no serviço por um período entre seis a 10 anos, 26,7\% entre 11 e 20 anos. Sobre o tempo de atuação no período noturno, 49,5\% relataram estar atuando no período noturno por um período entre seis a 10 anos e $23,8 \%$, entre
11 a 20 anos. O tempo em que um profissional de enfermagem permanece em um mesmo serviço pode ser considerado um fator estressor que interfere no desempenho da QV no trabalho, principalmente dos enfermeiros já que estes são normalmente responsáveis pela gestão do serviço $^{(22)}$. Em outra pesquisa, 25\% dos sujeitos pesquisados atuavam no período noturno por um período de tempo superior a oito anos ${ }^{(23)}$.

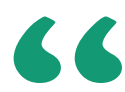

\section{Em relação à} raça, o estudo demonstrou que $63,8 \%$ se consideram de cor parda e $22,9 \%$ de cor branca. No que se refere ao estado civil, $79,0 \%$ são casados e $72,4 \%$ tem filhos.

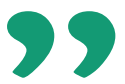

Os principais motivos que influenciaram os profissionais a optarem pelo trabalho noturno são: o interesse em meIhorar suas rendas, pois, neste horário os trabalhadores tem direito a um adicional noturno, e a possibilidade de conciliar outros empregos ${ }^{(11)}$. No entanto, em outro estudo, afirma-se que as condições noturnas são mais propícias a desencadear fa- tores negativos que podem, por sua vez, interferir na saúde dos trabalhadores, e conseqüentemente, reduzir a QV desses profissionais ${ }^{(22)}$. Isso fica evidenciado e foi demonstrado que os profissionais optaram pelo período noturno por questões financeiras e pessoais, tal como a dedicação à família( ${ }^{(19)}$.

Em relação a auxiliar de enfermagem, não se pôde considerar como uma variável possível de ser avaliada individualmente, mas ainda assim, é necessário salientar que este sujeito apresentou características bem distintas dos demais (técnicos e auxiliares de enfermagem), como estar numa faixa etária acima da média geral deste estudo, possuindo tendo entre 41 e 50 anos, ser de cor negra, divorciada, e ter um número maior que três filhos. A QV decorre de condições intrínsecas e extrínsecas ao ser humano e, portanto, não apenas as condições pessoais e socioeconômicas e demográficas serão suficientes para compreender totalmente os fatores intervenientes no desenvolvimento da QV das pessoas, principalmente quando esta qualidade pode ainda ser influenciada pelas condições de trabalho ${ }^{(5,8,10,13,17,19)}$. A maioria dos sujeitos exerce mais de uma carga horária de trabalho, ou seja, $67,6 \%$ do total da população participante da pesquisa possuem mais de um vínculo empregatício, e isso poderá interferir na QV e influenciar na satisfação desses trabalhadores, profissionais que possuem mais de um vínculo empregatício permanecem mais tempo no ambiente hospitalar e, por isso, encontram-se mais sujeitos aos riscos existentes nesses locais, em decorrência da acentuada exposição, seja ela física ou psicológica.

Quando essa dupla jornada se estabelece em horários diversos e na função de cuidador, é ainda mais preocupante, pois se exige destes profissionais maior atenção e minúcia. Uma dupla jornada de trabalho pode trazer prejuízos como o absenteísmo, aumento na possibilidade de acidentes de trabalho (AT), desinteresse no desenvolvimento profissional, apatia, 
refletindo-se diretamente na assistência prestada $^{(5,6,8,20)}$. No entanto, observaram que a dupla jornada de trabalho pode contribuir, de um lado, para a melhoria da situação financeira, mas no geral sabem que só isso não basta ${ }^{(19,22,23)}$. O fato de trabaIhar em mais de um emprego, deveria ser fator contribuinte para a melhoria da QV, já que, conseqüentemente, melhora a situação financeira dessas pessoas, mas, no entanto, estudos apontam que enfermeiros que possuem maior quantidade de vínculos empregatícios apresentam pior QV se comparados aos que possuem menos vínculos empregatícios ${ }^{(8,20,22)}$.

Além disso, outro fator relevante para quem trabalha no período noturno é o período destinado ao sono, ao estudarem a influência do trabalho noturno sobre a saúde dos enfermeiros, concluíram que a QV dos mesmos é influenciada, sobretudo, por dois aspectos, o sono/repouso e o cansaço/desgaste ${ }^{(18)}$. Descrevem uma QV satisfatória dos profissionais de enfermagem, mas apontam que o sono pode ser considerado como uma desvantagem para a QV uma vez que estes indivíduos dispõem de menos tempo para descanso o que contribui para o envelhecimento precoce, esgotamento mental e emocional e vida social prejudicada ${ }^{(19,20,23)}$.

O trabalho no período noturno apresenta aspectos positivos como maior tempo para estudar, maior chance de aumentar a renda familiar com um segundo emprego, mas, é imprescindível que o profissional respeite seus próprios limites já que este processo pode gerar desequilíbrios físicos o que poderá comprometer o desenvolvimento das suas atividades e a qualidade da assistência prestada ${ }^{(7)}$. No entanto, o desgaste físico é menos prejudicial que o desgaste psicológico/emocional, pois este nem sempre pode ser identificado com facilidade. E esse tipo de prejuízo é muito comum entre os profissionais de enfermagem que atuam no ambiente hospitalar, já que lidam constantemente com a morte e o sofrimento. Vale ressaltar que os problemas físicos podem também serem desencadeados por problemas psicológicos, como é o caso do stress ${ }^{(22)}$.

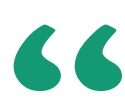

\section{Vale ressaltar que os problemas físicos podem também serem desencadeados por problemas psicológicos, como é o caso do stress.}

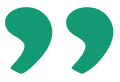

Nesta pesquisa, o escore de satisfação dos enfermeiros com sua saúde foi menor se comparado aos outros profissionais. Mesmo assim, constatou-se que a maioria dos sujeitos estava mais satisfeitos do que insatisfeitos com a saúde. Outras pesquisas associaram os problemas de saúde dos trabalhadores de enfermagem a uma redução na QV no trabalho, especialmente para os trabalhadores do período noturno por este ser responsável pelo desencadeamento de desequilíbrio nos hábitos alimentares, sono, capacidade de concentração, alterações no animo e na vida familiar e social ${ }^{(7,18)}$. Estudo realizado na região sudeste do país apontou que $80,0 \%$ dos profissionais de enfermagem classificaram sua saúde como boa, ainda que os domínios físico, psicológico e ambiental tivessem demonstrado uma QV reduzida(24).

É importante salientar que em todos os domínios o sexo feminino apresentou uma QV melhor que a do masculino, mas, as mulheres representaram a maioria neste estudo. Este dado também foi encontrado em estudo que objetivou avaliar a QV e a capacidade para o trabalho dos profissionais de enfermagem de um hospital de grande ${ }^{(5)}$. Em relação à comparação do estado civil e cargo desempenhado com os domínios, observou-se associação significativa em relação aos domínios psicológico e meio ambiente ${ }^{(25)}$.

Entre os domínios "físico", "psicológi-

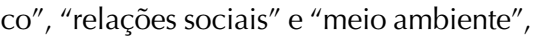
o domínio psicológico apresentou maior impacto sobre a QV dos sujeitos. Em outra pesquisa afirmam que o sofrimento psíquico gerado por longas jornadas de trabalho, ritmos acelerados de produção, pressão repressora e autoritária, inexistência ou escassez de pausas para o descanso ao longo das jornadas refletem em menor $\mathrm{QV}^{(8,20)}$. Salienta-se que o domínio relações sociais, o qual não apresentou associação considerável neste estudo, deve ser observado constantemente pelos serviços de saúde uma vez que é apontado por autores como intervenientes na QV dos profissionais da saúde. $\mathrm{O}$ trabalho noturno dificulta a manutenção da relação social, sobretudo, por esse horário causar certo isolamento social em função de não ser um turno comum ${ }^{(5,22,25)}$.

\section{CONCLUSÃO}

Trata-se de um estudo de cunho local, realizado apenas com a equipe de enfermagem noturna de apenas uma instituição hospitalar do município de Montes Claros. Sendo assim, a amostra torna-se insuficiente a fim de realizar uma análise comparativa mais aprofundada sobre os fatores que interferem em sua QV a nível local, caracterizando assim uma limitação do estudo. Ainda, o próprio desenho de estudo configura outra limitação, pois 
o estudo analítico transversal não é capaz de evidenciar a relação temporal entre o fator de risco e a doença, podendo prejudicar as inferências sobre a relação de causa e efeito, bem como não permitir a determinação do risco absoluto.

Este estudo demonstrou que os fatores "renda familiar", "prática de atividade física", "tempo de trabalho na institui- ção" e "tempo de atuação no período noturno" influenciaram negativamente na QV dos trabalhadores. Ainda que os participantes tenham classificado sua QV como boa, houve interferência negativa dos domínios "psicológico", "físico" e "meio ambiente" na QV em relação ao sexo, bem como do domínio "meio ambiente" em relação ao estado civil e do domínio "psicológico" e "meio ambiente" em relação ao cargo ocupado pelos sujeitos. Faz-se necessário que os serviços de saúde adotem medidas para proteger a saúde de seus trabalhadores da influência de fatores profissionais o que irá resultar em melhor QV dos profissionais, aumento da produtividade e melhoria da assistência prestada.

\section{Referências}

1. Raposo CFL, Silva ML. Princípios da administração científica: a revolução de Taylor. Rev. cient. inst. IDEIA [Internet]. 2017 [citado em30 jun2020];6(1):2958.doi: http://dx.doi.org/10.31219/osf.io/63jqz

2. Paganelli MP. 240 years of The Wealth of Nations. Nova econ. [Internet]. 2017 [citado em 30 jun 2020];27(2):7-19. doi: http://dx.doi.org/10.1590/0103$6351 / 3743$

3. Parra GD, Felli VEA. Processo de trabalho dos docentes de enfermagem. Rev. latinoam. enferm. [Internet]. 2017 [citado em 30 jun 2020];25:e2946. doi: http://dx.doi.org/10.1590/1518-8345.1941.2946

4. Velloso MP, Guimarães MBL, Cruz CRR, Neves TCC. Interdisciplinaridade e formação na área de saúde coletiva. Trab. educ. saúde [Internet]. 2016 [citado em 30 jun 2020];14(1):257-71. doi: http://dx.doi.org/10.1590/ 1981-7746-sip00097

5. Santos RR, Paiva MCMS, Spiri WC. Associação entre qualidade de vida e ambiente de trabalho de enfermeiros. Acta paul. enferm. [Internet]. 2018 [citado em 30 jun 2020];31(5):472-9. doi: http://dx.doi.org/10.1590/19820194201800067

6. Cardoso ACM. 0 trabalho como determinante do processo saúde-doença. Tempo soc. [Internet]. 2015 [citado em 30 jun 2020];27(1):73-93.doi: https:// dx.doi.org/10.1590/0103-207020150110

7. Silva RM, Beck CLC, Magnago TSBS, Carmagnani MIS, Tavares JP, Prestes FC. Trabalho noturno e a repercussão na saúde dos enfermeiros. Esc. Anna NeryRev. Enferm. [Internet]. 2011 [citado em 20 mai 2020];15(2):270-6.doi: http://dx.doi.org/10.1590/S1414-81452011000200008

8. Sousa KHJF, Zeitoune RCG, Portela LF, Tracera GMP, Moraes KG, Figueiró RFS Fatores associados aos riscos de adoecimento da equipe de enfermagem no trabalho em instituição psiquiátrica. Rev. latinoam. enferm. [Internet]. 2020 [citado em 30 jun 2020];28:e3235. doi: https://dx.doi.org/10.1590/15188345.3454 .3235

9. Ferreira SRS, Périco LAD, Dias VRGF. The complexity of the work of nurses in Primary Health Care.Rev. bras.enferm. [Internet]. 2018 [citado em 30 jun 2020];71(Supl 1):784-9. doi: http://dx.doi.org/10.1590/0034-7167-2017-0471 10. Carvalho EL, Silva MRB, Campelo SMA, Alencar DC, Moreira WC. Qualidade de vida dos trabalhadores de enfermagem de um centro de material e esterilização. Rev. interd. [Internet]. 2016 [citado em 30 jun 2020];9(3):67-73. Disponível em: https://dialnet.unirioja.es/descarga/articulo/6772024.pdf 11. Santana RS, Brito BAM, Ferreira JLS, Silva AFL, Cunha MB, Viana LVM. Influência do trabalho noturno na qualidade de vida da equipe de enfermagem da UTI.Rev. interd. [Internet]. 2015 [citado em 30 jun 2020];8(2):25-34. Disponível em: https://revistainterdisciplinar.uninovafapi.edu.br/index.php/revinter/ article/download/699/pdf_208

12. Oliveira MF, Grande AJ, Quadra MR, Doyenart R, Schäfer AA. Qualidade de vida e fatores associados em trabalhadores de uma Universidade do Sul de Santa Catarina. Cad. saúde colet. (Rio J.) [Internet]. 2020 [citado em 1 jul 2020];28(1):87-97. doi: https://doi.org/10.1590/1414-462×202028010327

13. Freire MN, Costa ER, Alves EB, Santos CMF, Santos CO. Qualidade de vida dos profissionais de enfermagem no ambiente laboral hospitalar. Rev. enferm. UFPE online [Internet]. 2016 [citado em 1 jul 2020];10(Supl. 6):4286-94.doi: http://dx.doi.org/10.5205/reuol.9284-81146-1-SM.1005sup201616

14. Freitag RMK. Amostras sociolinguísticas: probabilísticas ou por conveniên- cia? Rev. Estud. Ling. [Internet]. 2018 [citado em 26 nov 2020];26(2):667-86. doi: http://dx.doi.org/10.17851/2237-2083.26.2.667-686

15. Fleck MPA, Louzada S, Xavier M, Chachamovich E, Vieira G, Santos L et al. Aplicação da versão em português do instrumento abreviado de avaliação da qualidade de vida "WHOQOL-bref". Rev. Saúde Pública [Internet]. 2000 [citado em 23 nov 2020];34(2):178-83. doi: http://dx.doi.org/10.1590/S003489102000000200012

16. Brasil. Ministério da Saúde. Conselho Nacional de Saúde. Resolução nº 466, de 12 de dezembro de 2012. Regulamenta a realização de pesquisa envolvendo seres humanos. Brasília: Ministério da Saúde, 2012.

17. Paula AA, Gusmão AM, Maia LFS. Avaliação do perfil dos trabalhadores da enfermagem em pronto socorro. Rev. cient. enferm. [Internet]. 2017 [citado em 1 jul 2020];7(19):28-38.doi: https://dx.doi.org/10.24276/rrecien2358-3088.2017.7.19.28-38

18. Guerra PC, Oliveira NF, Terreri MTSLRA, Len CA. Sono, qualidade de vida e humor em profissionais de enfermagem em unidades de terapia intensiva infantil. Rev. Esc. Enferm. USP [Internet]. 2016 [citado em 1 jul 2020];50(2):27985. doi: http://dx.doi.org/10.1590/50080-623420160000200014

19. Reis FF, Braga ALS. O trabalho noturno e seus impactos na saúde da equipe de enfermagem: revisão integrativa. Rev. enferm. UFPE on line [Internet]. 2015 [citado em 1 jul 2020];9(3):7133-45.doi: http://dx.doi.org/10.5205/reuol.750565182-1-RV.0903201516

20. Sousa KHJF, Soares ECF, Moraes KG, Batista KC, Gonçalves TS, Zeitoune RCG. Fatores associados ao perfil da equipe de enfermagem de um hospital psiquiátrico e suas implicações para a saúde do trabalhador. REME rev. min. enferm. [Internet]. 2018 [citado em 1 jul 2020];22:e-1104.doi: http://dx.doi. org/10.5935/1415-2762.20180032

21. Machado MH, Aguiar Filho W, Lacerda WF, Oliveira E, Lemos W, Wermelinger $\mathrm{M}$, et al. Características gerais da enfermagem: o perfil sociodemográfico. Enferm. foco (Brasília) [Internet]. 2015 [citado em 1 jul 2020];6(1/4):11-7.doi: https://dx.doi.org/10.21675/2357-707X.2016.v7.nESP.686

22. Teixeira GS, Silveira RCP, Mininel VA, Moraes JT, Ribeiro IKS. Qualidade de vida no trabalho e estresse ocupacional da enfermagem em unidade de pronto atendimento. Texto \&contexto enferm. [Internet]. 2019 [citado em 1 jul 2020];28:e20180298. doi: https://dx.doi.org/10.1590/1980-265x-tce-2018-0298

23. Franco A, Castanharo J, Marinheiro TS, Joviliano RD. Qualidade de vida: o perfil do profissional de enfermagem atuante no período noturno. Rev. EPeQFafibe [Internet]. 2011 [citado em 1 jul 2020];1(3):70-84.Disponível em: http://unifafibe.com.br/revistasonline/arquivos/revistaepeqfafibe/sumario/20/16112011141929.pdf

24. Souza RB, Silva MJP, Nori A. Pronto-Socorro: uma visão sobre a interação entre profissionais de enfermagem e pacientes. Rev. gaúch. enferm. [Internet]. 2007 [citado em 1 jul 2018];28(2):242-9.Disponível em: https://seer.ufrgs.br/ RevistaGauchadeEnfermagem/article/view/3169/1740

25. Marques ALN, Ferreira MBG, Duarte JMG, Costa NS, Haas VJ, Simões ALA. Qualidade de vida e contexto de trabalho de profissionais de enfermagem na Estratégia Saúde da Família. Rev. Rene [Internet]. 2015 [citado em 1 jul 2020];16(5):672-81. doi: http://dx.doi.org/10.15253/21756783.2015000500008 
ANEXO I

Questionário Socioeconômico e Demográfico

Sexo:

(_) Masculino (_) Feminino

Faixa estaria (anos):

$\begin{array}{ll}\left(\_\right)[20,30] & \left(\_\right)[31,40] \\ (\longleftarrow)[41,50] & (\longleftarrow)[50,+]\end{array}$

Raça:

(_) Branco (_) Negro (_) Pardo

Estado civil:

(_) Solteiro (_) Casado

\section{Categoria profissional:}

(_) Enfermeiro

ANEXO II

Instrumento Abreviado de Avaliação de QV da OMS (WHOQOL-Bref)

Instruções

Este questionário é sobre como você se sente a respeito de sua quali-
(_) Técnico de Enfermagem

(_) Auxiliar de Enfermagem

\section{Participação financeira no grupo} familiar:

(_) Trabalho, mas recebo ajuda financeira da família.

(_) Sou responsável apenas pelo meu próprio sustento.

(_) Sou responsável pelo meu sustento e contribuo em casa.

(_) Sou o principal responsável pelo sustento da família.

\section{Renda do grupo familiar:}

(_) $<2$ salários mínimos.

(_) Três salários mínimos.

(_) Quatro salários mínimos.

dade de vida, saúde e outras áreas de sua vida. Por favor, responda a todas as questões. Se você não tem certeza sobre que resposta dar em uma questão, por favor, escolha entre as alternativas a que lhe parece mais apropriada. Esta, muitas vezes, poderá ser sua primeira escolha.
_ Cinco ou mais salários mínimos.

Tipo de imóvel em que reside:

(_) Próprio $\quad\left(\_\right)$Alugado
(_) Cedido Outra situação

Filhos:

(_) Nenhum (_) Um

(_) Dois (_) Três ou mais

\section{Religião:}

(_) Católico (_) Evangélico

(_) Adventista (_) Espírita

(_) Outras (_) Nenhuma

Estuda atualmente:

(_) Sim (_) Não

Por favor, tenham em mente seus valores, aspirações, prazeres e preocupações. Nós estamos perguntando o que você acha de sua vida, tomando como referência as duas últimas semanas. Por exemplo, pensando nas últimas duas semanas, uma questão poderia ser:

$\begin{array}{lccccc} & \text { Nada } & \text { Muito pouco } & \text { Médio } & \text { Muito } & \text { Completamente } \\ \text { Você recebe dos outros o apoio de que necessita? } & 1 & 2 & 3 & 4 & 5\end{array}$

Você deve circular o número que melhor corresponde ao quanto você recebe dos outros o apoio de que necessita nestas últimas duas semanas. Portanto, você deve circular o número 4 se você recebeu "muito" apoio como abaixo.

$\begin{array}{lccccc} & \text { Nada } & \text { Muito pouco } & \text { Médio } & \text { Muito } & \text { Completamente } \\ \text { Você recebe dos outros o apoio de que necessita? } & 1 & 2 & 3 & 4 & 5\end{array}$

Você deve circular o número 1 se você não recebeu "nada" de apoio. Por favor, leia cada questão, veja o que você acha e circule no número e lhe parece a melhor resposta.As questões seguintes são sobre o quanto você tem sentido algumas coisas nas últimas duas semanas.

$\begin{array}{ccccccc}\text { N } & \text { Variável } & \text { Nada } & \text { Muito pouco } & \text { Médio } & \text { Muito } & \text { Completamente } \\ 1 & \text { Como você avaliaria sua qualidade de vida? } & 1 & 2 & 3 & 4 & 5 \\ \text { N } & \text { Variável } & \text { MI } & \text { I } & \text { NSNI } & \text { S } & \text { MS } \\ 2 & \text { Quão satisfeito(a) você está com sua saúde? } & 1 & 2 & 3 & 4 & 5\end{array}$

Legenda: MI = Muito Insatisfeito; I = Insatisfeito; NSNI = Nem Satisfeito, Nem Insatisfeito; S = Satisfeito; MS = Muito Satisfeito.

As questões seguintes perguntam sobre quão completamente você tem sentido ou é capaz de fazer certas coisas nestas últimas duas semanas.

\begin{tabular}{|c|c|c|c|c|c|c|}
\hline $\mathrm{N}$ & Variável & Nada & Muito pouco & Mais ou Menos & Bastante & Extremamente \\
\hline 3 & $\begin{array}{l}\text { Em que medida você acha que sua dor (física) impede você de } \\
\text { fazer o que você precisa? }\end{array}$ & 1 & 2 & 3 & 4 & 5 \\
\hline
\end{tabular}


40 quanto você precisa de algum tratamento médico para levar sua vida diária?

\begin{tabular}{|c|c|c|c|c|c|c|}
\hline 5 & 0 quanto você aproveita a vida? & 1 & 2 & 3 & 4 & 5 \\
\hline 6 & Em que medida você acha que a sua vida tem sentido? & 1 & 2 & 3 & 4 & 5 \\
\hline 7 & 0 quanto você consegue se concentrar? & 1 & 2 & 3 & 4 & 5 \\
\hline 9 & $\begin{array}{l}\text { Quão saudável é o seu ambiente físico (clima, barulho, poluição, } \\
\text { atrativos)? }\end{array}$ & 1 & 2 & 3 & 4 & 5 \\
\hline
\end{tabular}

As questões seguintes perguntam sobre quão bem ou satisfeito você se sentiu a respeito de vários aspectos de sua vida nas últimas

\begin{tabular}{|c|c|c|c|c|c|c|}
\hline N & Variável & Nada & Muito pouco & Médio & Muito & Completamente \\
\hline 10 & Você tem energia suficiente para seu dia-a-dia? & 1 & 2 & 3 & 4 & 5 \\
\hline 11 & Você é capaz de aceitar sua aparência física? & 1 & 2 & 3 & 4 & 5 \\
\hline 12 & Você tem dinheiro suficiente para satisfazer suas necessidades? & 1 & 2 & 3 & 4 & 5 \\
\hline 13 & $\begin{array}{l}\text { Quão disponíveis para você estão as informações que precisa no seu } \\
\text { dia-a-dia? }\end{array}$ & 1 & 2 & 3 & 4 & 5 \\
\hline 14 & Em que medida você tem oportunidades de atividade de lazer? & 1 & 2 & 3 & 4 & 5 \\
\hline 8 & Quão seguro(a) você se sente em sua vida diária? & 1 & 2 & 3 & 4 & 5 \\
\hline 9 & Quão saudável é o seu ambiente físico (clima, barulho, poluição, atrativos)? & 1 & 2 & 3 & 4 & 5 \\
\hline
\end{tabular}

duas semanas.

As questões seguintes referem-se à com que freqüência você sentiu ou experimentou certas coisas nas últimas duas semanas.

$\begin{array}{llccccc}\mathbf{N} & \text { Variável } & \text { MR } & \text { R } & \text { NRNB } & \text { B } & \text { MB } \\ 15 & \text { Quão bem você é capaz de locomover? } & 1 & 2 & 3 & 4 & 5\end{array}$

Legenda: $M R=$ Muito Ruim; R = Ruim; NRNB = Nem Ruim, Nem Bom; B = Bom; MB = Muito Bom.

\begin{tabular}{|c|c|c|c|c|c|c|}
\hline $\mathbf{N}$ & Variável & MI & I & NSNI & $\mathbf{S}$ & MS \\
\hline 16 & Quão satisfeito(a) você está com seu sono? & 1 & 2 & 3 & 4 & 5 \\
\hline 17 & $\begin{array}{l}\text { Quão satisfeito(a) você está com sua capacidade de desempenhar as } \\
\text { atividades do seu dia-a-dia? }\end{array}$ & 1 & 2 & 3 & 4 & 5 \\
\hline 18 & Quão satisfeito(a) você está com sua capacidade para o trabalho? & 1 & 2 & 3 & 4 & 5 \\
\hline 19 & Quão satisfeito(a) você está consigo mesmo? & 1 & 2 & 3 & 4 & 5 \\
\hline 21 & Quão satisfeito(a) você está com sua vida sexual? & 1 & 2 & 3 & 4 & 5 \\
\hline 22 & Quão satisfeito(a) você está com o apoio que você recebe de seus amigos? & 1 & 2 & 3 & 4 & 5 \\
\hline 23 & Quão satisfeito(a) você está com as condições do local onde mora? & 1 & 2 & 3 & 4 & 5 \\
\hline
\end{tabular}

Legenda: $\mathrm{MI}=$ Muito Insatisfeito; I = Insatisfeito; NSNI = Nem Satisfeito, Nem Insatisfeito; S = Satisfeito; MS = Muito Satisfeito.

\begin{tabular}{|c|c|c|c|c|c|c|}
\hline $\mathrm{N}$ & Variável & Nunca & Algumas vezes & Freqüentemente & $\begin{array}{l}\text { Muito } \\
\text { freqüentemente }\end{array}$ & Sempre \\
\hline 26 & $\begin{array}{l}\text { Com que frequência você tem sentimentos negativos, tais } \\
\text { como mau humor, desespero, ansiedade, depressão? }\end{array}$ & 1 & 2 & 3 & 4 & 5 \\
\hline
\end{tabular}

